\title{
Assessment of Cancer Risks Associated with Patient Organ Doses from Medical Diagnostic Computed Tomography in Bangladesh
}

\author{
I Jahan ${ }^{1}$, Md Shakilur Rahman*2, A A Mamun ${ }^{1}$ and Tanjim Siddiqua ${ }^{2}$ \\ ${ }^{1}$ Department of Physics, Jahangirnagar University, Bangladesh \\ ${ }^{2}$ Secondary Standard Dosimetry Laboratory (SSDL), Bangladesh Atomic Energy Commission, Bangladesh
}

*Corresponding author: Md Shakilur Rahman, Secondary Standard Dosimetry Laboratory (SSDL), Bangladesh Atomic Energy

Commission, Bangladesh

\section{ARTICLE INFO}

Received: 豐 January 20, 2020

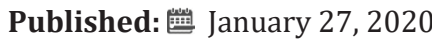

Citation: I Jahan, Md Shakilur Rahman, A A Mamun, Tanjim Siddiqua. Assessment of Cancer Risks Associated with Patient Organ Doses from Medical Diagnostic Computed Tomography in Bangladesh. Biomed J Sci \& Tech Res 25(1)-2020. BJSTR. MS.ID.004131.

Keywords: Ionizing Radiation; Computed Tomography; Effective Dose; Cancer Risk

\begin{abstract}
Along with the high-quality image, the enormous observance of CT in medical diagnosis delivers radiation doses to patients that are alarmingly higher than other modalities. Observance of entrance doses of patients undergoing selected diagnostic CT in Bangladesh, calculations of Effective Dose (ED) to analyze ED distribution and to determine the whole-body effect of exposure were carried out on Alderson Rando male human phantom maintaining IAEA TRS 457 protocols. Entrance doses of different organs were observed using IBA Kermax plus Tino DDP and pocket dosimeters. Corresponding specific ED (by conversion coefficient) and whole-body ED (by tissue weighting factor) were estimated from it. $\mathrm{ED}_{\mathrm{CC}}$ found in this study has a wide range from 0.30 to 395.00 $\mu \mathrm{Sv}$ for Head, 12.75 to $1075.00 \mu \mathrm{Sv}$ for Chest, 7.35 to $2578.80 \mu \mathrm{Sv}$ for abdomen and 2.40 to $3320 \mu \mathrm{Sv}$ for Gonad. EDwhole was calculated and further used to estimate risk factor and incident per population. Cancer risks estimated by risk calculator were found higher for chest and abdomen CT respectively $2.59 \times 10^{-2}(1: 3854)$ and $4.45 \times 10^{-2}(1: 2246)$ at the age of 25 and due to having double exposure. The results were compared with established international reference dose levels and found below reference dose levels.
\end{abstract}

Abbreviations: ED: Effective Dose; CT: Computed Tomography; NMPI: Nuclear Medical Physics Institute; SSDL: Secondary Standard Dosimetry Laboratory; IPEM: Institute of Physics and Engineering in Medicine

\section{Introduction}

Exposures resulting from medical radiological procedures involving ionizing radiation constitute the largest part of the population exposure from artificial radiation [1]. Striking technological advancement and splendid performance in the past two decades vindicate Computed Tomography (CT) as one of the prime established radiologic modalities lately. Determination of dose imparted to patients, monitoring and reduction of dose and finally assuring appropriate image quality to ameliorate the effective use of radiation are focused in the current study. It is important to spark attention over the long-term effect of CT because the organ doses from CT are found typically 100 times larger than those from conventional radiological procedures [2]. A quality assurance program for the CT would be emphasized based on the studies to reduce the patient dose and fatal cancer risk as well as to provide a basic data set for the determination of organ doses in CT. There is a need to control these doses and therefore to optimize the design and use of CT imaging systems. Bangladesh Bureau of Statistics claims cancer as the sixth leading cause of death in Bangladesh (BBS, 2004). There is a possibility of occurring malignancies due to tracing back the radiation from earlier CT exposure and at the same time radiation from CT studies currently being performed may ultimately account for $1.5 \%$ to $2 \%$ of all cancers in the future [3]. The thriving use of CT in susceptible populations and rising concerns on the part of the general public regarding radiation exposure have provided a spur for performing these studies with the least possible radiation dose [4]. 
The present work has been done for the assessment of radiation dose to patients and to optimize the dose in diagnostic CT. Some measurements were performed and comparisons of the measured data with established international reference dose levels were done for the entrance dose and estimated effective dose on Alderson Rando human phantom undergoing selected diagnostic CT. Experiments were held in the Nuclear Medical Physics Institute (NMPI), AERE, using different dose measuring equipment calibrated earlier in Secondary Standard Dosimetry Laboratory (SSDL), AERE, Savar, Dhaka, Bangladesh. Calculations and analyze of Effective Dose (ED) in CT examinations to determine fatal cancer risk from whole body effective dose using risk calculator are focused in this study.

\section{Materials and Methods}

Head, chest, abdomen and gonad CTs are the most frequently suggested CT scans in medical diagnosis. The main instrument used in the present study is ingenuity TF PET/CT, Philips of 128 slices located at NMPI, AERE. In lieu of actual patients Anderson Rando human phantom, which comprises ingredients similar to human tissue used to investigate the effect of radiation beams on human beings, has been used. Dosimetry protocols proposed by IAEA international code of practice TRS 457 and by the report no. 77, Institute of Physics and Engineering in Medicine (IPEM) were used to measure the quality control parameters [5,6]. Electronic personal dosimeters of PM1610 series provide measurement of dose equivalent. In this study four pocket dosimeters of PM1610 series were used holding the serial no 111163, 111190, 111277, 111269 [7]. IBA Kermax-Plus Tino DDP (M: 120-131 Tino) is a rectangular, transparent ionization chamber which calculates the dose within the radiation field [8]. This dosimeter was placed on the selected target organ to do CT with and pocket dosimeters were placed on the other concerned organs to measure the scattered dose. All CT scans have been performed at $120 \mathrm{KV}$ voltage keeping the scan length same for the selected organ and taking different time duration. Quality control tests such as CTDI (volume), mAs (mili ampere second), DLP (Dose Length Product) were also observed from the CT machine for different CT examinations. Entrance dose has been observed through direct measurement. Effective dose has been defined by the ICRP as the sum of the weighted equivalent doses to specified organs and provides a useful measure of radiation risk (ICRP, 1991) [9]. Conversion coefficients were used to relate entrance dose and ED (specific). ED from entrance dose was derived from the formula given below:

$$
E D=(m S v)=\text { Entrance dose }(m G y) \times C C_{\text {Entrance dose }}(m S v / m G y)
$$

where, the symbol has their usual meaning. $C C_{\text {Entrance dose }}$ was used from the table presented in report of NRPB [10]. Tissue weighting factor represents the proportion of the stochastic risk resulting from tissue to the total risk, when the whole body is irradiated uniformly [11]. The radiation weighting factor is the value selected for a specified type and energy of the radiation. To find whole body effective dose the entrance dose was multiplied by radiation weighting factor first and then multiplied by tissue weighting factor. This whole-body ED is mandatory for assessment of cancer risk using risk calculator. The following is used in this study to estimate ED (whole body) [10].

$$
E=\sum_{T} W_{T} H_{T}=\sum_{T} W_{T} \sum_{T} W_{R} D_{T, R},
$$

where, $W_{T}$ is the tissue weighting factor, and $H_{T}$ is the equivalent dose in that tissue or organ. $D_{T, R}$ is the mean absorbed dose in tissue T, due to radiation R. $W_{R}$ is the radiation weighting factor. Exposure from medical imaging might be a reason of occurring $1-3 \%$ of cancer worldwide [12]. X-RayRisk.com is an educational website that focuses on estimating this risk. It is a web-based calculator that allows patients to track their imaging details and estimate their personal risk on the basis of frequently asked questions. No published studies are available that can prove the direct causality between medical imaging and increased cancer risk. Information on cancer risk mostly comes from sources like the survivors of Hiroshima and Nagasaki atomic bombings and from the populations exposed medically, occupationally and environmentally.

\section{Results and Discussion}

Experiments were done for different target organs. Scan length for one specific organ was kept same and duration of time kept varying. To carry out a radiological imaging with more resemblance the concept of adequate quality control is necessary. A necessity of improvement in the standardization in CT imaging can be accomplished by the implementation of quality control. Not every organ is equally radiosensitive. During a CT scan radiosensitive organ may have more detrimental effects than others from radiation dose. List of technical parameters for different target organs in CT like target length, duration of scan, computed tomography dose index (volume), tube voltage, tube current-time (mAs) product, dose length products are shown in Table 1. Stochastic or probabilistic effects from low dose and its effects on human body can be related through effective dose [13]. It has been defined by the ICRP as the sum of the weighted equivalent doses to specified organs and provides a useful measure of radiation risk (ICRP, 1991). In all cases tube voltage was taken as $120 \mathrm{KV}$ and entrance doses were measured through IBA Kermax and pocket dosimeters for target organs and other organs respectively. Measured values have been multiplied by calibration factors of the instruments used and according to the above equation effective doses were estimated. Conversion coefficients were used to relate entrance dose and ED. It can be measured by computation rather than direct measurement. Accumulated and adverse health when the whole body is irradiated uniformly can be assessed by whole body ED using tissue weighting factor. EDs by conversion coefficient are shown in Tables 2-4 whole body ED and associated cancer risks for different organs are displayed for both single scan and double scan. 
Table 1: Calculated effective doses for target organs as well as other organs exposed.

\begin{tabular}{|c|c|c|c|c|c|c|}
\hline Examination Type & Length & $\operatorname{Tim}(\mathrm{sec})$ & CTDI (vol) mGy & KV & mAs & DLP (mGy*cm) \\
\hline \multirow{3}{*}{ Chest CT } & \multirow{3}{*}{327} & 15.05 & 9.2 & \multirow{12}{*}{120} & 141 & 350.7 \\
\hline & & 23.11 & 9.4 & & 147 & 357.9 \\
\hline & & 28.36 & 9.4 & & 147 & 356.2 \\
\hline \multirow{3}{*}{ Abdomen CT } & \multirow{3}{*}{270} & 6.16 & 13.8 & & 214 & 460.4 \\
\hline & & 13.9 & 13.9 & & 214 & 450.9 \\
\hline & & 19.73 & 13.9 & & 211 & 448.9 \\
\hline \multirow{3}{*}{ Gonad CT } & \multirow{3}{*}{195} & 5.38 & 14.4 & & 221 & 383.6 \\
\hline & & 10.34 & 14.4 & & 222 & 362.3 \\
\hline & & 15.62 & 14.4 & & 225 & 359.2 \\
\hline \multirow{3}{*}{ Head CT } & \multirow{3}{*}{215} & 9.41 & 58.1 & & 450 & 1557 \\
\hline & & 19.67 & 58.1 & & 450 & 1539 \\
\hline & & 28.67 & 58.1 & & 451 & 1538 \\
\hline
\end{tabular}

Table 2: Calculated effective doses for target organs as well as other organs exposed.

\begin{tabular}{|c|c|c|c|c|c|c|c|}
\hline \multirow{2}{*}{ Target Organ } & \multirow{2}{*}{ Voltage (KV) } & \multirow{2}{*}{ Length (mm) } & \multirow{2}{*}{ Time (sec) } & \multicolumn{4}{|c|}{ Effective Dose $(\mu \mathrm{Sv})$} \\
\hline & & & & Head & Chest & Abdomen & Gonad \\
\hline \multirow{3}{*}{ Chest } & \multirow{12}{*}{120} & \multirow{3}{*}{327} & 15.05 & 2.18 & 1013 & 111.3 & 9.6 \\
\hline & & & 23.11 & 2.7 & 1071 & 115.5 & 8.4 \\
\hline & & & 28.36 & 2.03 & 1075 & 103.95 & 9.6 \\
\hline \multirow{3}{*}{ Abdomen } & & \multirow{3}{*}{270} & 6.16 & 0.68 & 52.5 & 2578.8 & 409.2 \\
\hline & & & 13.9 & 0.75 & 51.75 & 2555 & 573.6 \\
\hline & & & 19.73 & 0.6 & 133.5 & 2559.2 & 579.6 \\
\hline \multirow{3}{*}{ Gonad } & & \multirow{3}{*}{195} & 5.38 & 0.3 & 12.75 & 127.05 & 3300.8 \\
\hline & & & 10.34 & 0.3 & 21.75 & 179.55 & 3216 \\
\hline & & & 15.62 & 0.3 & 25.5 & 226.8 & 3320 \\
\hline \multirow{3}{*}{ Head } & & \multirow{3}{*}{215} & 9.41 & 389.5 & 70.5 & 8.4 & 2.4 \\
\hline & & & 19.67 & 392.8 & 66 & 8.4 & 2.4 \\
\hline & & & 28.67 & 395 & 63.75 & 7.35 & 2.4 \\
\hline
\end{tabular}

Table 3: Whole body effective dose and risk factors for single and double CT scans for Head and Chest.

\begin{tabular}{|c|c|c|c|c|}
\hline \multirow{3}{*}{ Organ } & \multirow{3}{*}{ Age (years) } & \multirow{3}{*}{ Effective Dose (Whole Body) mSv } & \multicolumn{2}{|c|}{ Risk factor (\%): incident per population } \\
\hline & & & \multicolumn{2}{|c|}{ Number of CT } \\
\hline & & & 1 & 2 \\
\hline \multirow{12}{*}{ Head } & \multirow{3}{*}{25} & 0.39 & $3.917 \times 10^{-3}(1.25530)$ & $7.834 \times 10^{-3}(1: 12765)$ \\
\hline & & 0.39 & $3.950 \times 10^{-3}(1: 25316)$ & $7.900 \times 10^{-3}(1: 12658)$ \\
\hline & & 0.4 & $3.972 \times 10^{-3}(1: 25176)$ & $7.945 \times 10^{-3}(1: 12587)$ \\
\hline & \multirow{3}{*}{40} & 0.39 & $2.593 \times 10^{-3}(1: 38565)$ & $5.186 \times 10^{-3}(1: 19283)$ \\
\hline & & 0.39 & $2.615 \times 10^{-3}(1: 38241)$ & $5.260 \times 10^{-3}(1: 19120)$ \\
\hline & & 0.4 & $2.630 \times 10^{-3}(1: 38023)$ & $5.259 \times 10^{-3}(1: 19015)$ \\
\hline & \multirow{3}{*}{50} & 0.39 & $1.970 \times 10^{-3}(1: 50761)$ & $3.939 \times 10^{-3}(1: 25387)$ \\
\hline & & 0.39 & $1.986 \times 10^{-3}(1: 50352)$ & $3.973 \times 10^{-3}(1: 25170)$ \\
\hline & & 0.4 & $1.997 \times 10^{-3}(1: 50075)$ & $3.995 \times 10^{-3}(1: 25031)$ \\
\hline & \multirow{3}{*}{70} & 0.39 & $1.136 \times 10^{-3}(1: 88028)$ & $2.273 \times 10^{-3}(1: 43995)$ \\
\hline & & 0.39 & $\left.1.146 \times 10^{-3}(1: 87260)\right)$ & $2.292 \times 10^{-3}(1: 43630)$ \\
\hline & & 0.4 & $1.152 \times 10^{-3}(1: 86806)$ & $2.305 \times 10^{-3}(1: 43384)$ \\
\hline
\end{tabular}




\begin{tabular}{|c|c|c|c|c|}
\hline \multirow{12}{*}{ Chest } & \multirow{3}{*}{25} & 1.22 & $1.22 \times 10^{-2}(1.8180)$ & $2.45 \times 10^{-2}(1: 4090)$ \\
\hline & & 1.29 & $1.29 \times 10^{-2}(1: 7737)$ & $2.59 \times 10^{-2}(1: 3868)$ \\
\hline & & 1.29 & $1.30 \times 10^{-2}(1: 7708)$ & $2.59 \times 10^{-2}(1: 3854)$ \\
\hline & \multirow{3}{*}{40} & 1.22 & $8.09 \times 10^{-3}(1: 12356)$ & $1.62 \times 10^{-2}(1: 6178)$ \\
\hline & & 1.29 & $8.56 \times 10^{-3}(1: 11688)$ & $1.71 \times 10^{-2}(1: 5844)$ \\
\hline & & 1.29 & $8.59 \times 10^{-3}(1: 11644)$ & $1.72 \times 10^{-2}(1: 5822)$ \\
\hline & \multirow{3}{*}{50} & 1.22 & $6.15 \times 10^{-3}(1: 16268)$ & $1.23 \times 10^{-2}(1: 8134)$ \\
\hline & & 1.29 & $6.50 \times 10^{-3}(1: 15387)$ & $1.30 \times 10^{-2}(1: 7693)$ \\
\hline & & 1.29 & $6.52 \times 10^{-3}(1: 15330)$ & $1.30 \times 10^{-2}(1: 7665)$ \\
\hline & \multirow{3}{*}{70} & 1.22 & $3.55 \times 10^{-3}(1: 28193)$ & $7.093 \times 10^{-3}(1: 14098)$ \\
\hline & & 1.29 & $3.75 \times 10^{-3}(1: 26667)$ & $7.50 \times 10^{-3}(1: 13335)$ \\
\hline & & 0.4 & $1.152 \times 10^{-3}(1: 86806)$ & $2.305 \times 10^{-3}(1: 43384)$ \\
\hline
\end{tabular}

Table 4: Whole body ED and risk factors for single and double CT scans for Abdomen and Gonad CT.

\begin{tabular}{|c|c|c|c|c|}
\hline \multirow{3}{*}{ Organ } & \multirow{3}{*}{ Age (years) } & \multirow{3}{*}{ Effective Dose (Whole Body) mSv } & \multicolumn{2}{|c|}{ Risk factor (\%): incident per population } \\
\hline & & & \multicolumn{2}{|c|}{ Number of CT } \\
\hline & & & 1 & 2 \\
\hline \multirow{12}{*}{ Abdomen } & \multirow{3}{*}{25} & 2.21 & $2.23 \times 10^{-2}(1: 4491)$ & $4.45 \times 10^{-2}(1: 2246)$ \\
\hline & & 2.19 & $2.20 \times 10^{-2}(1: 4541)$ & $4.40 \times 10^{-2}(1: 2270)$ \\
\hline & & 2.19 & $2.21 \times 10^{-2}(1: 4533)$ & $4.41 \times 10^{-2}(1: 2267)$ \\
\hline & \multirow{3}{*}{40} & 2.21 & $1.47 \times 10^{-2}(1: 6784)$ & $2.95 \times 10^{-2}(1: 3392)$ \\
\hline & & 2.19 & $1.46 \times 10^{-2}(1: 6859)$ & $2.92 \times 10^{-2}(1: 3429)$ \\
\hline & & 2.19 & $1.46 \times 10^{-2}(1: 6847)$ & $2.92 \times 10^{-2}(1: 3424)$ \\
\hline & \multirow{3}{*}{50} & 2.21 & $1.12 \times 10^{-2}(1: 8932)$ & $2.24 \times 10^{-2}(1: 4466)$ \\
\hline & & 2.19 & $1.11 \times 10^{-2}(1: 9030)$ & $2.21 \times 10^{-2}(1: 4515)$ \\
\hline & & 2.19 & $1.11 \times 10^{-2}(1: 9015)$ & $2.22 \times 10^{-2}(1: 4508)$ \\
\hline & \multirow{3}{*}{70} & 2.21 & $6.46 \times 10^{-3}(1: 15482)$ & $1.29 \times 10^{-2}(1: 7741)$ \\
\hline & & 2.19 & $6.39 \times 10^{-3}(1: 15652)$ & $1.28 \times 10^{-2}(1: 7825)$ \\
\hline & & 2.19 & $6.4 \times 10^{-3}(1: 15625)$ & $2.8 \times 10^{-3}(1: 7813)$ \\
\hline \multirow{12}{*}{ Gonad } & \multirow{3}{*}{25} & 1.65 & $1.66 \times 10^{-2}(1: 6025)$ & $3.32 \times 10^{-2}(1: 3013)$ \\
\hline & & 1.61 & $1.62 \times 10^{-2}(1: 6184)$ & $3.23 \times 10^{-2}(1: 3092)$ \\
\hline & & 1.66 & $1.67 \times 10^{-2}(1: 5990)$ & $3.34 \times 10^{-2}(1: 2995)$ \\
\hline & \multirow{3}{*}{40} & 1.65 & $1.10 \times 10^{-2}(1: 9102)$ & $2.20 \times 10^{-2}(1: 4551)$ \\
\hline & & 1.61 & $1.07 \times 10^{-2}(1: 9341)$ & $2.14 \times 10^{-2}(1: 4671)$ \\
\hline & & 1.66 & $1.11 \times 10^{-2}(1: 9049)$ & $2.21 \times 10^{-2}(1: 4524)$ \\
\hline & \multirow{3}{*}{50} & 1.65 & $8.35 \times 10^{-3}(1: 11982)$ & $1.67 \times 10^{-2}(1: 5991)$ \\
\hline & & 1.61 & $8.13 \times 10^{-3}(1: 12299)$ & $1.63 \times 10^{-2}(1: 6149)$ \\
\hline & & 1.66 & $8.39 \times 10^{-3}(1: 11913)$ & $1.68 \times 10^{-2}(1: 5956)$ \\
\hline & \multirow{3}{*}{70} & 1.65 & $4.82 \times 10^{-3}(1: 20768)$ & $9.63 \times 10^{-3}(1: 10384)$ \\
\hline & & 1.61 & $4.69 \times 10^{-3}(1: 21317)$ & $9.38 \times 10^{-3}(1: 10658)$ \\
\hline & & 1.66 & $4.84 \times 10^{-3}(1: 20648)$ & $9.69 \times 10^{-3}(1: 10324)$ \\
\hline
\end{tabular}

For all CT examinations mentioned, typical ED (resulted from NRPB calculation method) were ranged from $0.3 \mu \mathrm{Sv}$ to $3320 \mu \mathrm{Sv}$. In case of whole-body ED (resulted from tissue weighting factor) the range was from $0.3 \mu \mathrm{Sv}$ to $2214 \mu \mathrm{Sv}$. Cancer risk factors were calculated using whole body EDs through the risk calculator. As Alderson Rando human phantom was used in this study, age of the patient was assumed. To understand the impact of age on dose, age $25,40,50$ and 70 were considered in this experiment. It is observed that risk factor decreases with the increase of age. Risks were found considering the number of scan as 1 (single exposure) and 2. It is evident that risks were increased with the increasing number of exposure. CT doses were compared with the internationally avowed data in (Table 4) and found within the safety limits (Table 5). It is difficult to compare the present data with reference data since almost each study has considered different phantom or irradiation conditions. To understand the impact of exposure deeply both male and female patients should be taken in consideration but in this research only male human phantom has been used. 
Table 5: Comparison of ED for selected organs worldwide.

\begin{tabular}{|c|c|c|c|c|c|c|}
\hline \multirow{2}{*}{ Organs } & \multicolumn{2}{|c|}{ Present Work (Dose in mSv) } & \multicolumn{2}{c|}{ Previous Works (Dose in mSv) } \\
\cline { 2 - 6 } & Typical ED & Whole Body ED & AAPM 96 [14] & D. Hart et el. NRPB W4 [10] & A. J. Van der Molen et.el. [15] & $\begin{array}{c}\text { Eugene C.Lin, Md } \\
\text { [16] }\end{array}$ \\
\hline Head & 0.4 & 0.4 & 2-Jan & 2 & $1.5-1.9$ \\
\hline Chest & 1.08 & 1.29 & 7-May & 8 & $7.7-8.6$ \\
\hline Abdomen & 2.56 & 2.19 & 7-May & 10 & $8-8.7$ \\
\hline Gonad & 3.32 & 1.66 & 4-Mar & 10 & 10 \\
\hline
\end{tabular}

\section{Conclusion}

The proper risk of malignancy from CT is a burning context of dispute [17]. Accurate carcinogenic risk from low doses of ionizing radiation involves uncertainty [14-16]. The current statistics show the gigantic growth of CT through the world and thus it will continue to contribute a significant portion of the collective dose delivered to the concerned people [14]. Bangladesh is a country of around 160 million people. The dose and associated cancer risks from CT has been scrutinized currently in the world and so as in Bangladesh [18-19]. The objectives of the present study are to minimize the health effects due to radiation and to minimize risk to the patient. ED per examination was found lower in Bangladesh than in other countries A quality assurance program for the CT would be emphasized based on the data acquired from present study to reduce the patient dose and fatal cancer risk. The data obtained in this study hopefully may add to the available information in national records for general use.

\section{References}

1. Furlow B (2010) Radiation Dose in Computed Tomography. Radiologic Technology 81: 437-450.

2. Hall EJ, Brenner DJ (2008) Cancer Risks from diagnostic radiology. The British Journal of Radiology 81: 362-378.

3. Dauer LT, Brooks AL, Hoel DG, Morgan WF, Stram D, et al. (2010) Review and evaluation of updated research on the health effects associated with low dose ionising radiation. Radiat Prot Dosimetry 140: 103-136.

4. Raman SP, Mahesh M, Blasko RV, Fishman EK (2013) CT Scan Parameters and Radiation Dose: Practical Advice for Radiologists. Journal of American College of Radiology 10(11): 840-846.

5. (2007) International Atomic Energy Agency, Dosimetry in Diagnostic Radiology: An International Code of Practice, Technical Reports Series No. 457, IAEA, Vienna, Austria.

6. Ranallo FN (1998) Recommended standards for the routine performance testing of diagnostic x-ray imaging systems, IPEM Report No. 77. 25(8): 1556-1557.

\section{ISSN: 2574-1241}

DOI: 10.26717/BJSTR.2020.25.004131

Md Shakilur Rahman. Biomed J Sci \& Tech Res

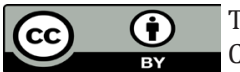

This work is licensed under Creative Commons Attribution 4.0 License

Submission Link: https://biomedres.us/submit-manuscript.php
7. (2019) Step Sensortechnik und Elektronik Pockau GmbH, Technical Specifications: Polimaster PM1610, created by HMS Multimedia Retrieved on 2 July.

8. IBA Dosimetry.

9. (1991) International Commission on Radiological Protection, Recommendations of the International Commission on Radiological Protection, ICRP Report 60, Annals of the ICRP 21:1/3.

10. Hart D, Wall BF (2002) Radiation Exposure of the UK population From Medical and Dental X-ray Examinations. August.

11. Martin A, Harbison SA (1979) An Introduction to Radiation Protection, ( $2^{\text {nd }}$ Edition) published in the U.S.A. by Chapman and Hall in association with Meuthuen Inc., New York.

12. Berrington de González A, Darby S (2004) Risk of cancer from diagnostic X-rays: Estimates for the UK and 14 other countries. Lancet 363(9406): 345-351.

13. Tsapaki V, Tsalafoutas IA, Chinofoti I, Karageorgi A, Carinou E, et al. (2007) Radiation doses to patients undergoing standard radiographic examinations: A comparison between two methods. The British Journal of Radiology 80(950): 107-112.

14.(2008) American Association of Physicists in Medicine, The measurement, Reporting, and Management of Radiation Dose in CT, Report of AAPM Task Group 23 of the Diagnostic Imaging Council CT Committee, Report No. 96.

15. Van der Molen AJ, Schilham A, Stoop P, Prokop M, Geleijns J (2013) A national survey on radiation dose in CT in The Netherlands. Insights Imaging 4: 383-390.

16. Eugune C, Lin MD (2010) Radiation Risk from Medical Imaging. Mayo Clin Proc. 85: 1142-1146.

17. Albert JM (2013) Radiation Risk From CT: Implications for Cancer Screening. AJR Am J Roentgenol 201(1): W81-W87.

18. Noronha V, Tsomo U, Jamshed A, Hai MA, Wattegama S, et al. (2012) A fresh look at oncology facts on south central Asia and SAARC countries. South Asian J Cancer 1(1): 1-4.

19. Kamal Uddin AF M, Khan ZJ, Islam J, Mahmud AM (2013) Cancer care scenario in Bangladesh. South Asian J Cancer 2(2): 102-104.

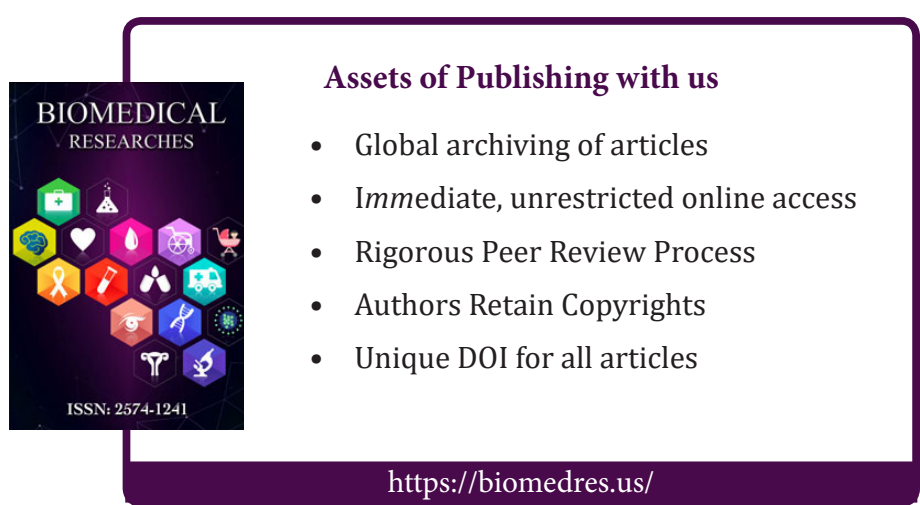

